\title{
Flow-injection Spectrophotometric Determination of $N$-acetyl-L-cysteine Based on Coupled Redox-complexation Reaction
}

\author{
Lea Kukoč - Modun, ${ }^{*}$ Ivana Plazibat, and Njegomir Radić \\ Department of Analytical Chemistry, Faculty of Chemistry and Technology, \\ University of Split, Teslina 10/V, 21000 Split, Croatia
}

RECEIVED SEPTEMBER 21, 2010; REVISED FEBRUARY 9, 2011; ACCEPTED FEBRUARY 11, 2011

\begin{abstract}
A flow-injection spectrophotometric method is developed for determination of $N$-acetyl-Lcysteine (NAC) in pharmaceutical formulations. The method is based on coupled redox-complexation reaction, the first step of which is the reduction of $\mathrm{Fe}^{\mathrm{III}}$ by $\mathrm{NAC}$; the second one includes the complexation of $\mathrm{Fe}^{\mathrm{II}}$, resulting from the preceding redox reaction, with 2,4,6-tripyridyl-s-triazine (TPTZ). The stable $\mathrm{Fe}(\mathrm{TPTZ})_{2}{ }^{2+}$ complex exhibits an absorption maximum at $\lambda=593 \mathrm{~nm}$. Under experimental conditions, optimized by univariate method, a linear calibration curve is established in NAC concentration range from $6.0 \times 10^{-6} \mathrm{~mol} \mathrm{~L}^{-1}$ to $2.0 \times 10^{-4} \mathrm{~mol} \mathrm{~L}^{-1}$ with NAC detection limit of $2.0 \times 10^{-6} \mathrm{~mol} \mathrm{~L}^{-1}$. The analytical frequency was $60 \mathrm{~h}^{-1}$. Usual excipients used as additives in pharmaceuticals do not interfere with the analysis of NAC. The proposed method is simple, rapid, sensitive, accurate and precise (repeatability RSD $0.29 \%$, $n=10$ ), and can be applied for determination of NAC in pharmaceutical formulations up to nanomole quantity. (doi: 10.5562/cca1753)
\end{abstract}

Keywords: $N$-acetyl-L-cysteine; flow-injection spectrophotometry; pharmaceuticals

\section{INTRODUCTION}

$N$-Acetyl-L-cysteine (NAC) is a synthetic aminothiol antioxidant with a mucolytic effect, shown to be effective in the management of paracetamol (acetaminophen) poisoning. In addition, it is being studied and utilized for curing HIV infection, cancer and heart disease. ${ }^{1}$

Several analytical methods have been reported for NAC determination in pharmaceutical formulations, including spectrophotometry, ${ }^{2-7}$ fluorimetry, ${ }^{8,9}$ chromatography ${ }^{10,11}$ and electrochemistry. ${ }^{12,13}$ Some of the methods described above are not simple for direct application in a large-scale routine analysis and require expensive or sophisticated instruments.

In recent years, more strict regulation related to the quality control in pharmaceuticals led to increasing demands on automation of the analytical assays carried out in appropriate control laboratories. The flowinjection analysis (FIA) became a versatile instrumental tool that contributed substantially to the development of automation in pharmaceutical analysis due to its simplicity, low cost and relatively short analysis time. ${ }^{14}$

There are several published flow-injection methods for the determination of NAC with potentio- metric $^{15,16}$ and spectrophotometric detector. ${ }^{17-23}$ Described flow-injection spectrometric methods have adequate sample analysis frequency but, on the other hand, narrow analytical range and lack of sensitivity. Fatibello-Filho and co-workers use in their studies laboratoryconstructed (custom-made) manual injector-commutator as part of flow-injection system. ${ }^{19-21}$ This manual injector-commutator is commercially not available and hence not obtainable for use in other labora-tories.

In this work 2,4,6-tripyridyl-s-triazine (TPTZ) was proposed as a chromogenic reagent for the determination of NAC in aqueous laboratory samples, instead of frequently employed 1,10-phenantroline. ${ }^{5,21}$ The use of TPTZ as chromogenic reagent has improved selectivity, linearity and sensitivity of measurements. Reaction mechanism of the method is based on the coupled redox-complexation reaction between $\mathrm{NAC}, \mathrm{Fe}^{\mathrm{III}}$ and TPTZ. The coloured complex of Fe ${ }^{\text {II }}$ with TPTZ was monitored at $\lambda=593 \mathrm{~nm}$. A simple flow-injection system for NAC determination was developed. The proposed procedure is simple, inexpensive, does not involve any pre-treatment procedure and has a high sample analysis frequency. The method was successfully applied for determination of NAC in pharmaceutical formulations.

\footnotetext{
* Author to whom correspondence should be addressed. (E-mail: 1kmodun@gmail.com)
} 


\section{EXPERIMENTAL}

\section{Instrumentation}

The flow-injection manifold for spectrophotometric determination of NAC is shown in Figure 1. The set-up consisted of a Shimadzu UV-1601 (Shimadzu, Kyoto, Japan) UV/Vis spectrophotometer equipped with a flow cell of $160 \mu \mathrm{L}$ internal volume and $10 \mathrm{~mm}$ optical path. The instrument was set at $\lambda=593 \mathrm{~nm}$ for all absorbance measurements and the output signals were recorded by coupling the spectrophotometer to a computer equipped with Hyper UV software provided by Shimadzu. An Ismatec IPC eight-channel peristaltic pump (Ismatec, Zurich, Switzerland), equipped with flexible Tygon tubes (grey/grey $1.30 \mathrm{~mm}$ I.D.), was used to deliver sample, sample carrier and reagent solution. A Rheodyne low pressure Teflon six port rotary valve, Model 5020 (Anachem, Luton, UK) was employed to inject samples and standard solutions into the system. The manifold was built up with polytetrafluoroethylene (PTFE) tubes with $0.8 \mathrm{~mm}$ bore and with Chemifold Type II (Tecator, USA). Adjustments and measurements of $\mathrm{pH}$ were carried out with a Mettler Toledo SevenMulti potentiometer (Mettler Toledo, Schwerzenbach, Switzerland) equipped with combined glass electrode Mettler Toledo InLab ${ }^{\circledR} 413$.

A thermostated constant temperature water bath accurate to $\pm 0.5^{\circ} \mathrm{C}$ was used.

\section{Materials}

All chemicals were of analytical-reagent grade, and solutions were prepared with deionised water. All stock solutions were stored at $4{ }^{\circ} \mathrm{C}$ in dark bottles.

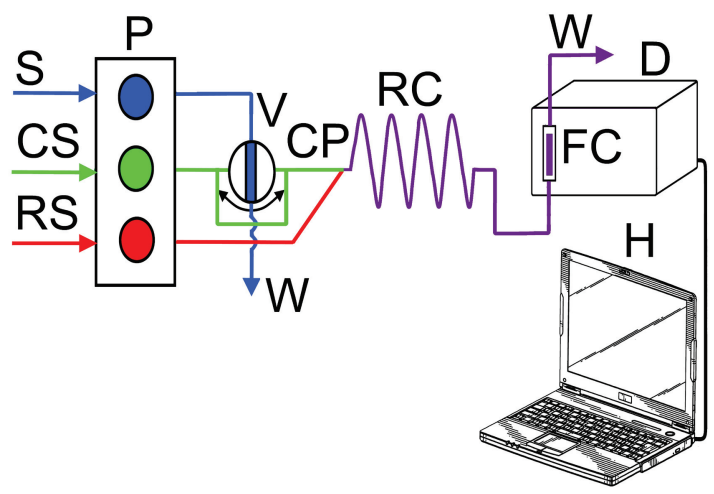

Figure 1. Flow-injection manifold configuration. S: sample or standard solution (NAC); CS: carrier stream (ultra pure water); RS: reagent stream $\left(1.0 \times 10^{-3} \mathrm{~mol} \mathrm{~L}^{-1} \mathrm{Fe}^{\mathrm{III}}\right.$ and $1.0 \times 10^{-3}$ mol L ${ }^{-1} \mathrm{TPTZ}$ in acetate buffer solution, $\mathrm{pH}=3.6$ ); $\mathrm{P}$ : peristaltic pump (flow rate $2.0 \mathrm{~mL} \mathrm{~min}^{-1}$ ); $\mathrm{V}$ : injector valve (loop = $500 \mu \mathrm{L}$ ); CP: confluence point; RC: reactor in coiled form (length: $300 \mathrm{~cm}$, i.d. $0.8 \mathrm{~mm}$ ); D: spectrophotometric detector $(\lambda=593 \mathrm{~nm})$ equipped with flow cell $(\mathrm{FC}, 160 \mu \mathrm{L}) ; \mathrm{H}$ : computer; W: waste.
A stock solution of NAC $\left(1.0 \times 10^{-2} \mathrm{~mol} \mathrm{~L}^{-1}\right)$ was prepared by dissolving $163.2 \mathrm{mg}$ of NAC in $100.0 \mathrm{~mL}$ of deionised water. Working solutions of lower concentration were prepared daily by appropriate dilution of the stock solution with deionised water.

A stock solution of $\mathrm{Fe}^{\mathrm{III}}\left(1.0 \times 10^{-2} \mathrm{~mol} \mathrm{~L}^{-1}\right)$ was prepared by dissolving $270.3 \mathrm{mg}$ of $\mathrm{FeCl}_{3} \times 6 \mathrm{H}_{2} \mathrm{O}$ in a portion of deionised water, to which $0.5 \mathrm{~mL}$ of concentrated hydrochloric acid was added, before making up to a volume of $100.0 \mathrm{~mL}$.

A stock solution of TPTZ, $1.0 \times 10^{-2} \mathrm{~mol} \mathrm{~L}^{-1}$, was prepared by dissolving $312.3 \mathrm{mg}$ in $2.0 \mathrm{~mL}$ of $\mathrm{HCl}$ $\left(c(\mathrm{HCl})=6.0 \mathrm{~mol} \mathrm{~L}^{-1}\right)$, and diluted to $100.0 \mathrm{~mL}$ with deionised water.

Acetate buffer solutions $\left(c=0.5 \mathrm{~mol} \mathrm{~L}^{-1}\right)$ covered the $\mathrm{pH}$ range 3.2 to 4.0 . For the $\mathrm{pH}$ range 1.0 to 2.0 solutions of $0.1 \mathrm{~mol} \mathrm{~L}^{-1} \mathrm{HCl}(\mathrm{pH}=1.0)$ and $0.01 \mathrm{~mol} \mathrm{~L}^{-1}$ $\mathrm{HCl}(\mathrm{pH}=2.0)$ were used.

\section{Sample Preparation}

The commercial pharmaceutical formulations analysed by developed flow-injection spectrophotometric method were granules, Fluimukan $100 \mathrm{mg}$, syrup, Fluimukan Akut Junior and dispersible tablets, Fluimukan Akut $600 \mathrm{mg}$, all produced by Lek, Ljubljana, Slovenia. The contents of five granules units were powdered in a mortar and an accurately weighed portion of the homogenized powder containing about $100 \mathrm{mg}$ of NAC was transferred to a $250 \mathrm{~mL}$ volumetric flask and diluted to a nominal volume with deionised water. The $5 \mathrm{~mL}$ portion of syrup, containing about $100 \mathrm{mg}$ of NAC, was transferred to a $250 \mathrm{~mL}$ volumetric flask and diluted to a nominal volume with deionised water. One dispersible tablet was dissolved in $1000 \mathrm{~mL}$ of deionised water. Additional dilutions (10/1000) were necessary to obtain a final concentration of a sample solution that was analysed using proposed flow injection procedure.

\section{Flow-injection Procedure}

In the developed flow system, depicted in Figure 1, the loop $(500 \mu \mathrm{L})$ of the rotary valve was filled with the sample (or standard solution) while the ultra pure water carrier stream (CS) was mixed with the reagent solution (RS: $1.0 \times 10^{-3} \mathrm{~mol} \mathrm{~L}^{-1} \mathrm{Fe}^{\mathrm{III}}$ and $1.0 \times 10^{-3} \mathrm{~mol} \mathrm{~L}^{-1} \mathrm{TPTZ}$ in acetate buffer solution, $\mathrm{pH}=3.6$ ), yielding the final stream that allowed the establishment of the baseline. By valve switching, the sample or standard solutions were injected (in triplicates) in the carrier stream, and thus formed sample zone flowed to the confluence point (CP) where it was mixed with reagent stream. The selected analytical frequency was $60 \mathrm{~h}^{-1}$. For confluence point Chemifold Type II (Tecator, USA) has been used. The final stream subsequently flowed to the reactor (RC) in coiled form (length: $300 \mathrm{~cm}$, i.d. $0.8 \mathrm{~mm}$, which corresponds to a volume of $1.50 \mathrm{~mL}$ ) where the coupled reaction took place. After colour development, the 
Table 1. Optimization of chemical parameters for the coupled redox-complexation reaction

\begin{tabular}{|c|c|c|}
\hline Parameters & $\begin{array}{l}\text { Studied } \\
\text { range }\end{array}$ & $\begin{array}{l}\text { Optimal } \\
\text { conditions }\end{array}$ \\
\hline $\mathrm{pH}$ value & $1.0-4.0$ & 3.6 \\
\hline molar ratio $\mathrm{Fe}^{\mathrm{III}} / \mathrm{NAC}$ & $0.5-10.0$ & 5.0 \\
\hline molar ratio TPTZ/NAC & $0.5-10.0$ & 5.0 \\
\hline reaction temperature $/{ }^{\circ} \mathrm{C}$ & $25-50$ & 30 \\
\hline
\end{tabular}

dispersed sample zone reached the flow cell unit positioned in the optical path of the spectrophotometer (D) and the absorbance was continuously monitored at 593 $\mathrm{nm}$, yielding a transient signal. The peak height was employed as quantitative variable.

Throughout the measurement, all the solutions (sample, standard, carrier and reagent solution) and the reactor in coiled form were thermostated in the water bath.

\section{RESULTS AND DISCUSSION}

The proposed method is based on a coupled redoxcomplexation reaction. In the first (redox) step of the reaction, NAC reduces $\mathrm{Fe}^{\mathrm{III}}$ to $\mathrm{Fe}^{\mathrm{II}}$. In the second step of the reaction, the reduced $\mathrm{Fe}^{\mathrm{II}}$ is immediately converted to the highly stable $\mathrm{Fe}(\mathrm{TPTZ})_{2}{ }^{2+}$ complex with well-defined absorption maximum at $593 \mathrm{~nm}$. The kinetic properties of this coupled redox-complexation reaction were the subject of our previously reported batchwise kinetic method. ${ }^{24}$

\section{Optimization of Flow-injection and the Chemical Conditions}

Optimization of manifold parameters and experimental conditions were carried out by means of univariate method, ${ }^{25}$ in which a variable was modified while maintaining the other variables at their constant values (selected by random). Then by maintaining that variable at its optimum value, another was modified and this procedure was repeated for all variables.

The optimal chemical conditions ( $\mathrm{pH}$ value, concentrations of $\mathrm{Fe}^{\mathrm{III}}$ and TPTZ, temperature) for the coupled redox-complexation reaction, established in the previous kinetic study, ${ }^{24}$ have been confirmed for the flow-injection method (Table 1).

The previous kinetic study ${ }^{24}$ has shown that elevating the reaction temperature increases the rate of the considered reaction. However, due to the specificity of flow-injection system, the effect of temperature (presented with model equation: $A=0.017 t-0.09$ ) has a limitation. At temperatures higher than $30{ }^{\circ} \mathrm{C}$ the baseline signal was not stable as a result of the air bubbles formed in the flow system. Therefore, a temperature of $30{ }^{\circ} \mathrm{C}$ was selected as a compromise between the sensitivity of the method and the reproducibility of the flow system. Performing the analysis at ambient laboratory conditions reduced the sensitivity of measurements but the reproducibility and repeatability were unaffected.

\section{Effect of Sample Injection Volumes}

In the flow systems, the sample volume injected controls the amount of analyte inserted for reaction. In general, when sample volume is increased the analytical signal also increased. In the present case, sample loops with volumes of $100 \mu \mathrm{L}$ to $1000 \mu \mathrm{L}$ were tested. The absorbance signal importantly increased up to $500 \mu \mathrm{L}$, and volumes above $500 \mu \mathrm{L}$ gave only a small increase in peak height. Additionally, for volumes higher than $500 \mu \mathrm{L}$, the time spent to complete the transient signal was enlarged, which decreased the frequency of the system. Therefore, the sample volume of $500 \mu \mathrm{L}$ was selected as a compromise with respect to the method sensitivity and the high sample throughput.

\section{Effect of Length of the Reactor in Coiled Form}

The length of the reactor in coiled form controls the reaction time between reagent and sample (analyte) inside the FIA system. When longer reactor was used, the contact time between NAC and reagent solution increased before the sample zone passed through the flow cell, concomitantly increasing the yield of the reaction. Also, in this situation, the mixing of the carrier (sample) and reagent streams is improved, which minimizes the baseline noise. On the other hand, excessive increase of this variable can cause a decrease of analytical signal due to the increase of sample plug dispersion. The effect of reactor length was examined by varying the length from $100 \mathrm{~cm}$ to $525 \mathrm{~cm}$ (which is equivalent to volumes of $0.50 \mathrm{~mL}$ to $2.64 \mathrm{~mL}$ ). The signal intensity increased with increasing the length of the reactor up to $300 \mathrm{~cm}$, and for longer reactors, signal intensity remained almost identical. A reactor length of $300 \mathrm{~cm}$ was chosen as a compromise with respect to the sensitivity and the sample throughput.

\section{Effect of Flow Rate}

The effect of the flow rate of the carrier and reagent solution was investigated in the range of $0.5 \mathrm{~mL} \mathrm{~min}^{-1}$ to $4.0 \mathrm{~mL} \mathrm{~min}^{-1}$. The results indicate that with increasing flow rate, the sensitivity of the detection of NAC is lowered though the sampling frequency is higher. Considering the sensitivity and the sample throughput, the flow rate of $2.0 \mathrm{~mL} \mathrm{~min} \mathrm{mas}^{-1}$ wasen in the further experiments. Under optimized conditions sampling rate was 60 determinations per hour. The return time, defined as the period between the appearance of the NAC signal maximum at concentrations $\leq 2.0 \times 10^{-4} \mathrm{~mol} \mathrm{~L}^{-1}$ and the return to the baseline, was less than $0.6 \mathrm{~min}$. No baseline shift or absorbance drift was observed throughout the 1 hour run.

Under optimised conditions, the yield of coupled redox-complexation reaction was $60 \%$. This was ex- 


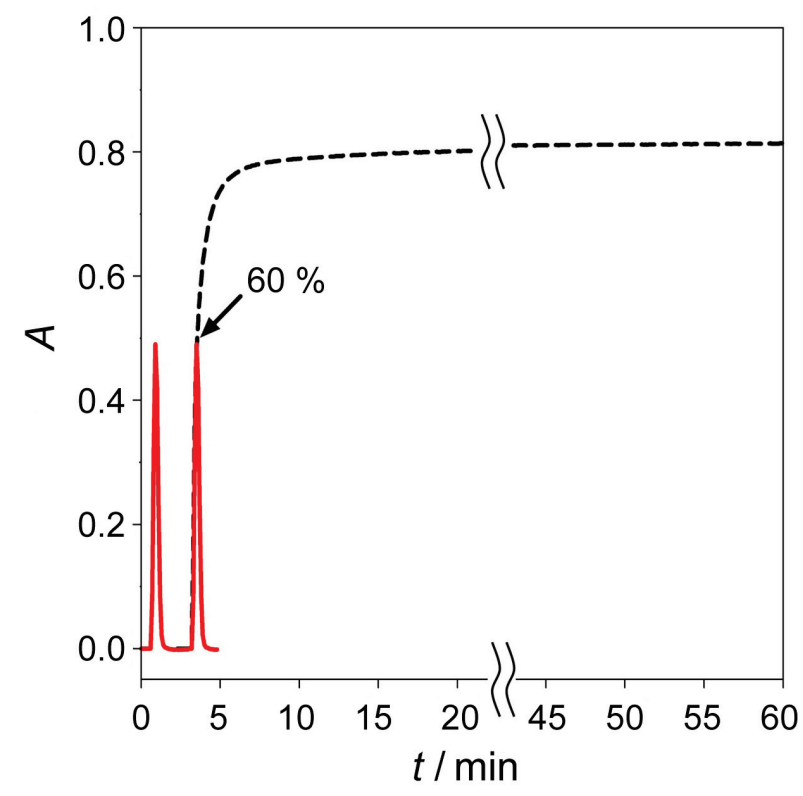

Figure 2. The yied of coupled redox-complexation reaction examined by stop-flow experiment. Experimental conditions: $c(\mathrm{NAC})=1.0 \times 10^{-4} \mathrm{~mol} \mathrm{~L}^{-1}$; reagent solution: $c\left(\mathrm{Fe}^{\mathrm{III}}\right)=$ $1.0 \times 10^{-3} \mathrm{~mol} \mathrm{~L}^{-1}, c(\mathrm{TPTZ})=1.0 \times 10^{-3} \mathrm{~mol} \mathrm{~L}^{-1}, \mathrm{pH}=3.6$; $t=30{ }^{\circ} \mathrm{C}$.

amined by using stop-flow experiment. The centre of the sample zone was stopped in the flow cell and kinetic of the reaction was continuously monitored for 1 hour afterwards (Figure 2).

\section{Effect of Internal Volume of Flow Cell}

The effect of internal volume of flow cell on signal intensity was studied by changing the volume from $80 \mu \mathrm{L}$ to $500 \mu \mathrm{L}$. By increasing the volume of flow cell, the return time was increasing and the signal intensity was decreasing. On the other hand, while performing the experiment at the optimal temperature $\left(30^{\circ} \mathrm{C}\right)$, baseline shifts were observed when the flow cell with smallest volume $(80 \mu \mathrm{L})$ was used. Therefore, the flow cell with internal volume of $160 \mu \mathrm{L}$ was chosen for further experiments.

\section{Analytical Characteristics}

Under the above-described optimum conditions, calibration curve was constructed covering the NAC concentration range from $6.0 \times 10^{-6} \mathrm{~mol} \mathrm{~L}^{-1}$ to $2.0 \times 10^{-4} \mathrm{~mol} \mathrm{~L}^{-1}$. Figure 3 shows a fiagram obtained by analysis of different NAC standards. Linear regression analysis of peak height $(y)$ versus NAC concentration $(x)(n=9)$ yielded the equation: $y=4.95 \times 10^{3} x-0.028\left(r^{2}=0.9994\right)$. The limit of detection (LOD) and the limit of quantification (LOQ) were calculated and found to be $2.0 \times 10^{-6}$ $\mathrm{mol} \mathrm{L}^{-1}$ and $6.0 \times 10^{-6} \mathrm{~mol} \mathrm{~L}^{-1}$, respectively. Spectral characteristics: apparent molar absorptivity and Sandell's sensitivity were calculated from the kinetic experimental results, and found to be $3.60 \times 10^{3} \mathrm{~L} \mathrm{~mol}^{-1} \mathrm{~cm}^{-1}$ and

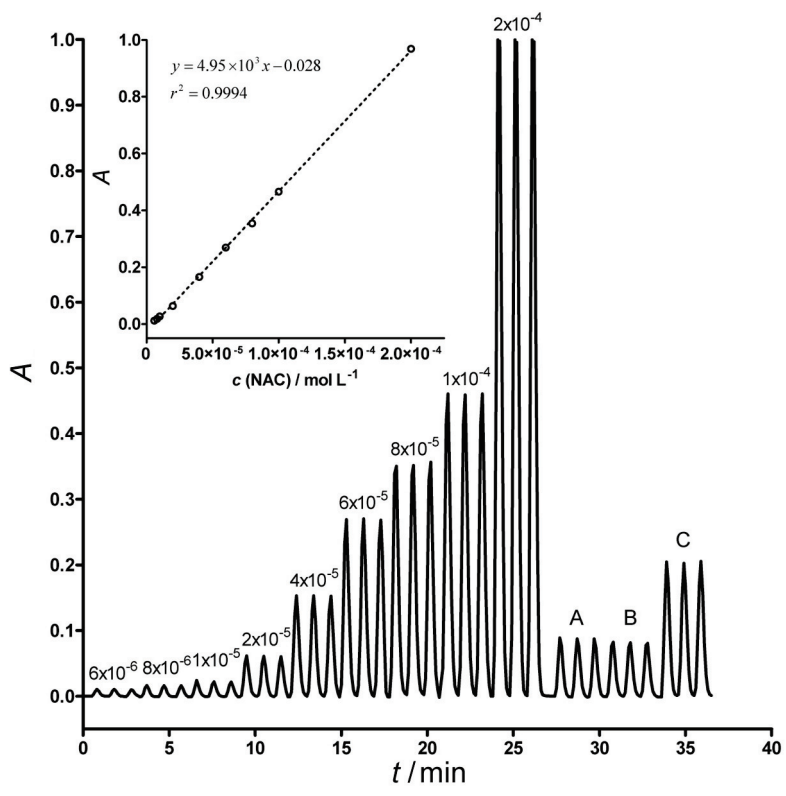

Figure 3. Fiagram chart and calibration curve (inlet) for spectrophotometric determination of NAC over the concentration range from $6.0 \times 10^{-6} \mathrm{~mol} \mathrm{~L}^{-1}$ to $2.0 \times 10^{-4} \mathrm{~mol} \mathrm{~L}^{-1}$. Fiagram includes recorded peaks for three samples: Fluimukan Granules (A); Fluimukan Akut Junior Syrup (B), and Fluimukan Akut Dispersible Tablets (C).

$4.5 \times 10^{-2} \mu \mathrm{g} \mathrm{cm}^{-2}$. At this point it should be stressed that the relative standard deviation of the slope of three calibration curves obtained on different working days with freshly prepared reagents, was smaller than $1.0 \%$.

\section{Repeatability}

The repeatability of the proposed method was assessed by carrying out ten consecutive injections of $1.0 \times 10^{-4}$ mol L ${ }^{-1}$ standard solution on a single occasion. The RSD of the measured peak heights was $0.29 \%$. This was considered to be satisfactory.

\section{Interferences Studies}

The effect of some possibly interfering cations and anions on the determination of NAC was investigated at a fixed NAC concentration $\left(4.0 \times 10^{-5} \mathrm{~mol} \mathrm{~L}^{-1} \mathrm{NAC}\right)$ with different amounts of foreign ions in order to determine the maximum tolerable foreign ion to NAC molar ratio. The influence of excipients that can commonly accompany NAC in pharmaceutical formulations was also studied. The tolerable concentration of $\mathrm{K}^{+}$, $\mathrm{Na}^{+}, \mathrm{CO}_{3}{ }^{2-}$ and $\mathrm{HCO}_{3}{ }^{-}$was $4.0 \times 10^{-2}$ mol L ${ }^{-1}$ (ion to NAC molar ratio $1000: 1)$ and the tolerable concentration of glucose, fructose, sucrose, boric acid and acetic acid was $2.0 \times 10^{-3} \mathrm{~mol} \mathrm{~L}^{-1}$ (excipient to NAC molar ratio 500:1). The tolerable concentration of some other thiols (D-penicillamine, L-glutathione and L-cysteine) was $4.0 \times 10^{-5} \mathrm{~mol} \mathrm{~L}^{-1}$ (thiol to NAC molar ratio $1: 1$ ). 
Table 2. Evaluation of accuracy of flow-injection spectrophotometric method for the determination of NAC in pharmaceutical formulations

\begin{tabular}{|c|c|c|c|}
\hline Sample & $\begin{array}{c}\text { Added } \\
\gamma / \mu \mathrm{g} \mathrm{mL} L^{-1}\end{array}$ & $\begin{array}{c}\text { Found }^{(\mathrm{a})} \\
\gamma / \mu \mathrm{g} \mathrm{mL} L^{-1}\end{array}$ & Recovery / \% \\
\hline \multirow{5}{*}{$\begin{array}{l}\text { Fluimukan } \\
\text { Granules }^{(b)}\end{array}$} & 0.0 & $102 \pm 2$ & - \\
\hline & 50.0 & $151 \pm 2$ & 99 \\
\hline & 100.0 & $201 \pm 2$ & 99 \\
\hline & 150.0 & $254 \pm 2$ & 102 \\
\hline & 200.0 & $298 \pm 3$ & 98 \\
\hline \multirow{5}{*}{$\begin{array}{l}\text { Fluimukan } \\
\text { Akut } \\
\text { Dispersible } \\
\text { Tablets }^{\left({ }^{c}\right)}\end{array}$} & 0.0 & $101 \pm 1$ & - \\
\hline & 50.0 & $151 \pm 2$ & 100 \\
\hline & 100.0 & $199 \pm 2$ & 98 \\
\hline & 150.0 & $252 \pm 2$ & 101 \\
\hline & 200.0 & $300 \pm 3$ & 100 \\
\hline \multirow{5}{*}{$\begin{array}{c}\text { Fluimukan }^{\text {Akut }} \\
\text { Junior Syrup }^{(d)}\end{array}$} & 0.0 & $100 \pm 1$ & - \\
\hline & 50.0 & $151 \pm 1$ & 101 \\
\hline & 100.0 & $199 \pm 2$ & 99 \\
\hline & 150.0 & $248 \pm 2$ & 98 \\
\hline & 200.0 & $303 \pm 3$ & 102 \\
\hline
\end{tabular}

(a) Average of three determinations $\pm \mathrm{SD}$.

(b) Granules containing NAC 100 mg and excip.

(c) Dispersible tablets containing NAC $600 \mathrm{mg}$ and excip.

(d) Syrup containing NAC $100 \mathrm{mg}$ in $5 \mathrm{~mL}$ and excip.

Table 3. Mass (average of three determinations \pm SD) of NAC in pharmaceutical formulations determined by the method reported in the literature ${ }^{2}$ and the proposed flowinjection spectrophotometric method

\begin{tabular}{ccc}
\hline Sample & $\begin{array}{c}\text { FIA method } \\
\mathrm{m} / \mathrm{mg}\end{array}$ & $\begin{array}{c}\text { Reported method }{ }^{2} \\
\mathrm{~m} / \mathrm{mg}\end{array}$ \\
\hline Fluimukan $^{(\mathrm{a})}$ & $102 \pm 2$ & $103 \pm 3$ \\
$\begin{array}{c}\text { Fluimukan } \\
\text { Akut Junior }\end{array}$ & $100 \pm 1$ & $101 \pm 1$ \\
$\begin{array}{c}\text { Fluimukan } \\
\text { Akut }\end{array}$ & $603 \pm 4$ & $607 \pm 7$ \\
\hline
\end{tabular}

(a) Granules containing NAC $100 \mathrm{mg}$ and excip.

(b) Syrup containing NAC $100 \mathrm{mg}$ in $5 \mathrm{~mL}$ and excip.

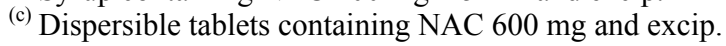

The tolerance limit is defined as the foreign ion or excipient to analyte concentration ratio causing an error smaller than $\pm 5 \%$ for determining the analyte of interest. The pigment present in some samples did not interfere in the absorbance measurements, which could be attributed to the low volume of the sample solution injected. It is worth mentioning that the absorbance measurement was performed in the visible region, away from the UV-absorption region of the possibly dissolved UV-absorbing excipient materials in the NACcontaining pharmaceutical formulations.

\section{Accuracy}

The accuracy of measurements was checked by carrying out recovery studies. In this procedure, known amounts of the NAC standard solution, at levels of $(50.0,100.0$, $150.0,200.0) \mu \mathrm{g} \mathrm{mL} \mathrm{m}^{-1}$, were added to preanalysed pharmaceutical formulations. Recoveries varied from $98 \%$ to $102 \%$, as shown in Table 2 . These results prove good accuracy of the proposed method and the absence of interferences from common excipients, indicating that the method is reliable for determination of NAC in pharmaceutical formulations.

\section{Application}

In order to evaluate the potential of the proposed method for the analysis of real samples, flow-injection spectrophotometric procedure was applied to different pharmaceutical formulations: granules (sample A), syrup (sample B), and dispersible tablets (sample C) for the determination of NAC. Recorded peaks referring to samples $\mathrm{A}, \mathrm{B}$, and $\mathrm{C}$ are shown in the Figure 3. As shown in Table 3, there were no significant differences between the results obtained by the method reported in the literature ${ }^{2}$ and those obtained by the method developed in this study $(P>0.1$, student $t$-test $)$.

\section{Conclusion}

In summary, a simple, rapid and sensitive flow-injection spectrophotometric method for the determination of NAC has been successfully developed and validated. By using TPTZ as the chromogenic agent the fast colour development reaction could be conducted easily at mild temperature conditions $\left(30^{\circ} \mathrm{C}\right)$. The proposed method has several advantages over previously reported flowinjection spectrophotometric methods: higher sensitivity, ${ }^{17-20,22}$ use of commercially available equipment ${ }^{19-21}$ and use of minimum number of reagents and reaction sequence. ${ }^{19}$ Additional advantages of the method are the wide linearity range and the very good reproducibility of calibration curves from day to day. The developed flow-injection spectrophotometric method was applied successfully for the determination of NAC in pharmaceutical formulations. Complex pre-treatment of the samples is not necessary: they are prepared simply by dissolving the pharmaceutical formulations in water. Usual excipients do not need to be removed since they do not interfere with the determination of NAC. These advantages encourage the application of the proposed method in the routine analysis of NAC in quality control laboratories.

Acknowledgements. This work was supported by the Ministry of Science, Education and Sports, Republic of Croatia, through Grant No. 011-0000000-3217. 


\section{REFERENCES}

1. G. S. Kelly, Altern. Med. Rev. 3 (1998) 114-127. PMid:9577247

2. M. A. Raggi, V. Cavrini, and A. M. Di Pietra, J. Pharm. Sci. 71 (1982) 1384-1386.

3. M. A. Eid, Mikrochim. Acta 129 (1998) 91-95. doi:10.1007/BF01246854

4. F. Buhl and M. Galkowska, Chem. Anal. (Warsaw) 51 (2006) 623-629.

5. M. C. Garcia Alvarez-Coque, M. J. Medina Hernandez, R. M. Vilanueva Camanas, and C. Mongay Fernandez, Analyst 114 (1989) 975-977.

6. T. S. Jovanović and B. S. Stanković, Analyst 114 (1989) 401403.

7. A. Martinović, L. Kukoč-Modun, and N. Radić, Anal. Lett. 40 (2007) 805-815.

8. M. Al-Ghannam Sh A. M. El-Brashy, and B. S. Al-Farhan, Farmaco 57 (2002) 625-629.

9. E. A. Taha, N. Y. Hassan, F. A. Aal, and S. Fattah Lel, J. Fluoresc. 17 (2007) 293-300.

10. B. Toussaint, C. Pitti, B. Streel, A. Ceccato, P. Hubert, and J. Crommen, J. Chromatogr. A 896 (2000) 191-199.

11. J. Farquhar, G. Finlay, P. A. Ford, and M. Martin-Smith, J. Pharm. Biomed. Anal. 3 (1985) 279-285.

12. S. Shahrokhiana, Z. Kamalzadeha, A. Bezaatpourc, and D. M. Boghaeia, Sens. Actuators B 133 (2008) 599-606.
13. J. Komljenović and N. Radić, Acta Pharm. 43 (1993) 99-106.

14. P. R. S. Ribeiro, J. A. G. Neto, L. Pezza, and H. R. Pezza, Talanta 67 (2005) 240-244.

15. M. Kolar and D. Dobcnik, Pharmazie 58 (2003) 25-28.

16. N. Radić and J. Komljenović, Fresenius J. Anal. Chem. 360 (1998) 675-678.

17. C. Sanchez-Pedreno, I. Albero, S. Garcia, and V. Rodenas, Analyst 117 (1992) 925-928.

18. M. J. Medina Hernandez, M. C. Garcia Alvarez-Coque, E. Bonet Domingo, and R. M. Villanueva Camanas, Pharmazie 45 (1990) 745-747.

19. W. T. Suarez, H. J. Vieira, and O. Fatibello-Filho, J. Pharm. Biomed. Anal. 37 (2005) 771-775.

20. W. T. Suarez, H. J. Vieira, and O. Fatibello-Filho, J. Braz. Chem. Soc. 18 (2007) 1028-1033.

21. A. L. De Toledo Fornazari, W. T. Suarez, H. J. Vieira, and O. Fatibello-Filho, Acta Chim. Slov. 52 (2005) 164-167.

22. W. T. Suarez, A. A. Madi, F. C. Vicentini, and O. Fatibello-Filho, Anal. Lett. 40 (2007) 3417-3429.

23. A. Martinović, Š. Cerjan Stefanović, and N. Radić, J. Chem. Metrol. 2 (2008) 1-12.

24. L. Kukoč-Modun and N. Radić, Anal. Sci. 26 (2010) 491-495.

25. A. San Vicente, A. Arranz, J. M. Moreda, and J. F. Arranz, Anal. Chim. Acta 298 (1994) 87-90. 